\title{
High Precision Work Station Research
}

\author{
X.M. Cheng \\ School of Material Engineering \\ Ningbo University of Technology \\ Ningbo, China \\ Y.Q. Chen \\ School of Material Engineering \\ Ningbo University of Technology \\ Ningbo, China \\ P.N. Zhang \\ School of Material Engineering \\ Ningbo University of Technology \\ Ningbo, China
}

\author{
H.C. Fan \\ School of Mechanical Engineering \\ Ningbo University of Technology \\ Ningbo, China \\ Z. Zhao \\ School of Mechanical Engineering \\ Ningbo University of Technology \\ Ningbo, China \\ C.Z. $\mathrm{Li}$ \\ School of Mechanical Engineering \\ Ningbo University of Technology \\ Ningbo, China
}

\begin{abstract}
- a wide range of high precision work station can today be using various fields. The position precision will directly determine the precision and ultra precision processing equipment machining accuracy. It is necessary to research highly precise station system. In this paper, the development of a two-dimensional worktable with high accuracy is presented. This work station uses the linear motor as the driving source. First of all, the components of the station technology and its control system are described. The latter comprises a grating scale sensor system for position measuring. The accuracy and repeatability of work station achieved high requirements.
\end{abstract}

Keywords-high precision; work station; linear motor; close loop control

\section{INTRODUCTION}

With the development of advanced manufacturing technology, the machining accuracy is increased more higher in industrial fields of military, microelectronics, micro machinery. High precision work station have become a core issue, pose estimation as a research hot in the field of manufacture research has been carried on for many years. The is sue of study here are the manufacturing technology, driving technology, controlling technology and measuring technology. There are a large number of studies including those technologies and some methods about the high precision station. Tokyo Institute of Technology developed a nano-positioning stage. The system uses a DC motor and air screw as the hydrostatic drive system, with hydrostatic bearings support the rotating screw. The entire table is completed using aerostatic support and guide rails. By laser interferometer as a feedback device, using closed-loop control, laser interferometer resolution up $0.3 \mathrm{~nm}$, positioning accuracy can be achieved with disabilities across the table $4 \mathrm{~nm}[1,2]$. Compiegne University of Technology in France developed a high-precision table. The table uses a brushless DC motor friction drive as drive and with hydrostatic support rails as the entire table. The maximum speed is up to $10 \mathrm{~mm} / \mathrm{s}$ and the positioning accuracy is up to 16nm [3].Shanghai University in China introduces the key techniques used for getting high precision and resolution. A control system based on macro-micro dual loop method is represented in which a macro stage is driven by ball screw and AC servo motor with metal reflect grating inspector to comprise servo control system. The linear compensation to the real error curve can reduce the position error from $76 \mu \mathrm{m}$ to $3 \mu \mathrm{m}$. A novel micro stage holds on the macro stage's upper surface. The detected error signal from macro loop will be changed to micro loop and can fulfill large stroke with nano precision positioning [4]. Cristiana Delprete focuses on a particular case study belonging to the bio-mechanical field. The research then has started with an exhaustive analysis of the state of the art, followed by the design and the practical realization of a manipulator matching the specific implementation but whose characteristics could be employed also for other applications [5].

Research on high-precision positioning stage from the drive mode aspects, can be used in many different forms-driven approach, such as ball screws, hydrostatic lead screw, piezoelectric ceramic and linear motors. Methods and levels can be directly positioned from a combination of macro and micro aspects of the structure of the table. In addition, high-precision positioning control method of the stage also diverse.However, those systems are very complexwith too many parts. This article mainly focuses on the high precision station based on linear motor and grating scale measure sensor.

\section{SeTting UP OF MECHANICAL SYSTEM}

High-precision work station system mainly consists of drive system, guidance system, measure system and control system 
and other components. Drive system is to determine the key for the whole table positioning accuracy. Feed accuracy and resolution of the drive system directly determines the positioning accuracy of the station. High-precision station feed can include two structural forms which is single-stage feed and two-stage feed. Two-stage feed refers to the macro and micro-positioning feed combined. It gets even nanometer or sub-nanometer positioning accuracy of general application in small displacement situations. In this paper, two-dimensional work station requires precision $\mathrm{XY}$ axis of the effective stroke $500 \mathrm{~mm}$ and $400 \mathrm{~mm}$, respectively. Positioning accuracy required to achieve micron. So the system uses a single-stage form of the feed structure.

\section{A. Diver Motor Selection}

Traditional precision drive mechanism mainly refers to use the ball screw. Ball in motion the process to rolling friction instead of sliding friction. The structure has a simple structure, low friction, high transfer efficiency, motion stability and long life, etc which widely used in precision processing areas. But the ball screw drive system drive chain length, component complexity, and there is accumulated pitch error and backlash errors, it is difficult to meet the requirements of high-precision positioning applications. Although the high level of precision ball screws can achieve micron level positioning accuracy and repeatability of positioning accuracy. But the cost is high. It's difficult to control.

Linear motor drive technology has a simple structure, get a larger movement speed and acceleration. And the stroke is not limited, to achieve the required precision positioning feed movement. Linear motor drive technology is increasingly used in precision and ultra-precision machining fields. This thesis studied precision dimensional table with linear motor drive technology. Achieve large stroke and high precision positioning requirements.

Permanent magnet linear synchronous motor mover consists of a three-phase armature windings hollow coil windings by epoxy encapsulation magnet on the inside of the support block and considerate. The stator and the overall structure of a "U" shaped groove structure. The mover reciprocates in the groove. The biggest difficulty of " $U$ " shaped hollow permanent magnet linear synchronous motor is mounting accuracy and uniformity that the mover of the permanent magnet air gap during moving. It has a large normal suction due to the contrary in the " $U$ " groove opposite polarity of two permanent magnets. It needs to ensure that the support block tightly close together when the installation of the permanent magnet of the permanent magnet. The length of " $U$ " type magnet design can not be too long affected control accuracy. The length is too long to cause non-uniformity of the air gap and to affect the accuracy of the hollow type servo control of permanent magnet linear synchronous motor. In applications where a large stroke in order to ensure the uniformity of the air gap, generally a plurality of magnets fixed length splicing. The linear motor is shown in Figure1.

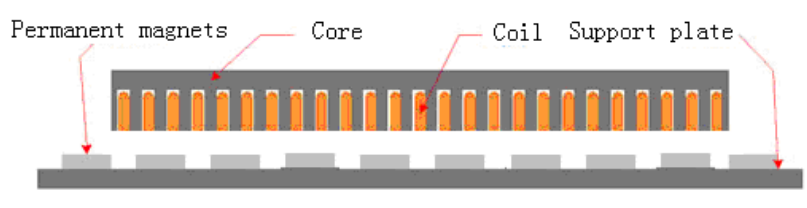

FIGURE I. "U” TYPE LINEAR MOTOR.

\section{B. Sensor and Measure Device}

Displacement measure device is an important part of the closed-loop control and semi-closed loop control, directly determines the accuracy of high hydrostatic mobile platform. There are many kinds of means for measure the displacement of the mobile platform. Here we select the grating displacement sensor to consist the measure system. Grating is mainly used for high-precision measurement of the displacement. The grating systemincludes a grating scale raster and a raster scanning head. The grating scale is fixed to the fixed table. The raster scanning head is fixed on the table moving parts.

\section{System introduce}

The work station used the marble slabs as the substrate. Marble slabs unaffected by temperature, no distortion. Marble slabs while long-term placement, it will not be deformed due to internal stresses. The work station has $\mathrm{x}, \mathrm{y}$ two-dimensional directions. Each direction used permanent magnet linear synchronous motor. X-direction stroke is designed for $400 \mathrm{~mm}$ and Y-direction stroke is $300 \mathrm{~mm}$. The linear guide stroke is selected as the support element. This linear guide stroke has many advantages as lower friction, good straightness and easy installation. The grating ruler is mounted in the middle of the work stage. There has a very higher parallel degree requirement between the liner guide stroke and the line motor and the grating ruler. Respectively the table cushion is mounted on both ends to protect against shock bumps. There is a standard installation flat above the table easy to install other components. The work station structure is shown in Figure2.

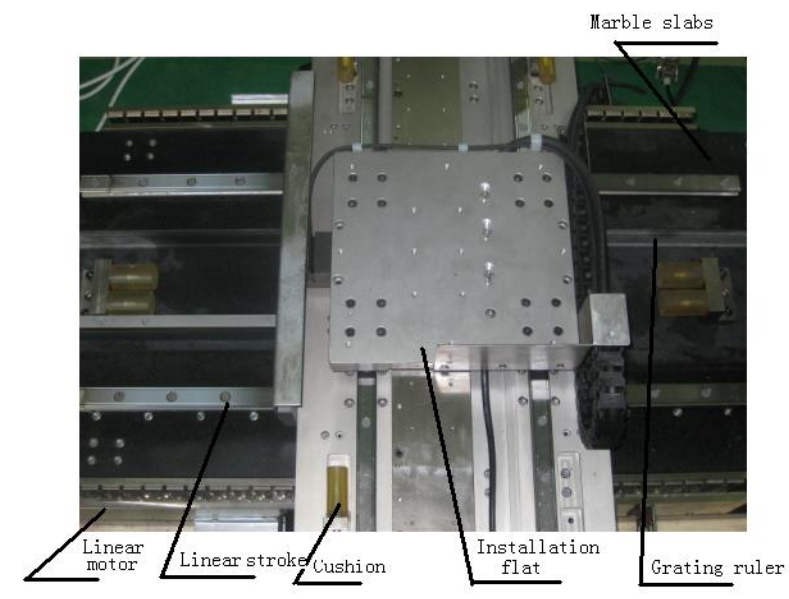

FIGURE II. WORK ST ATION. 


\section{Control System}

Closed-loop control method is to achieve the actual position of the controlled object and feedback to controller which generates a position error between the detected position and the control position. By controlling principle of the deviation to reduce bias. Theoretically closed-loop servo control system can eliminate all intermediate transmission errors caused by the transmission mechanism. Positioning accuracy of the system depends on the accuracy of the measure element. It would cause great difficulties to commissioning transmission vice friction characteristics, and other nonlinear factors clearance system. These features make the system performance decline and even cause oscillation. Closed-loop control of the system has high demands to control strategy. The system achieves a direct drive to eliminate all intermediate gear. Output displacement linear motor is the actual output table displacement. Everything nonlinear factors outside interference will directly affect the positioning accuracy of the station. In order to produce the effects of various disturbances on the effective correction, direct-drive systemcan only use closed loop control. To prevent electromagnetic interference of linear motor itself on the position of the sensor, the nearly actual position of the measured signal is fed back to the motion control card. After the control card digital operation, the control card sends a new control signal to control the motors. The whole experiences consist of a closed loop control systems. The system can achieve high precision positioning requirements. The close-loop control system shown in Figure3.

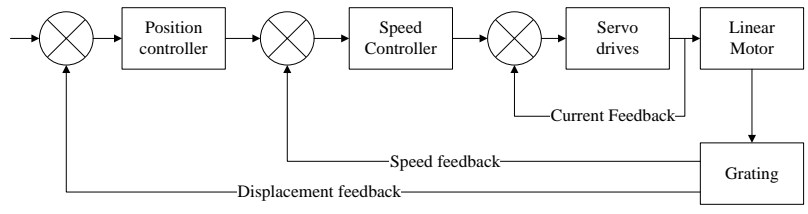

FIGURE III. SERVO PRINCIPLE STRUCTURE.

\section{SYSTEM TEST}

After commissioning the system is optimized to run at the optimal state. The station system is tested to meet the requirements of high-precision work station. The length of $\mathrm{x}$-direction is $500 \mathrm{~mm}$ and $\mathrm{y}$ direction is $400 \mathrm{~mm}$. The work station is running at maximum speed $1 \mathrm{~m} / \mathrm{s}$. The positioning accuracy is $5 \mu \mathrm{m}$ and the repeat positioning accuracy is $1 \mu \mathrm{m}$. The maximum acceleration is $10 \mathrm{~m} / \mathrm{s}^{2}$.

\section{CONCLUSION}

In this paper, our current efforts on the development of a high precision work station were presented. The linear motors are employed to perform move function. The components of the station and its control systemwere described. We discussed the work station components: an assembly using the marble; a sensor measure using the linear grating; a closed loop mode for the control system. After Adjusted and optimized, the station meets the requirements of high-precision. The project here presented has been a very good way for developing the high precision system in the particular field application giving the beginning of the work station.

\section{ACKNOWLEDGEMENT}

The work was supported by National Natural Science Foundation of China (NSFC, Grant Nos. 51275251 and 51075217), Zhejiang Provincial Natural Science Foundation of China (ZJSFC, Grant No. Y1100528).

\section{REFERENCES}

[1] J. H. Mao, H. Tachikawa, A. Shimokohbe. Double-inte gratoreontrol for Preeision Positioning in the Preseneeo ffrietion $[\mathrm{J}]$. Precision Engineering, 2003 (27): 419-428.

[2] J. H. Mao, H. Taehikawa, A. Shimokohbe. Preeision Positioning of a DC-motor-driven aero statieslide system [J]. Preeision Engineering, 2003(27):32-41.

[3] Mekid, Samir. High Precision linear slide. Partl: Design and eonstruetion $[\mathrm{J}]$. Intemational Journal of Machine Toolsand Manufaeture, 2000, 40(7): 1039-1050.

[4] L. Z. Sun, M. M. LI , W. M. Cheng. Study on precision positioning technique. Optics and Precision Engineering. 2005, Vol.13, Nov: 69-75.

[5] Cristiana Delprete, Carlo Rosso, Cristina Scarzella. New concept for micro-manipulation systems: a practial experience. Int J Adv Manuf Technol (2014) 74:1077-1085. 